\title{
Perpustakaan Sebagai Organisasi Pembelajar: Studi Perpustakaan Universitas Gadjah Mada**
}

\author{
Nur Cahyati Wahyuni* \\ email: ncahyati@ugm.ac.id \\ Martina Uki* \\ email: martinauki@ugm.ac.id
}

\begin{abstract}
A university library as a learning space should put learning as a major issue. As the organization itself, university library needs to measure its quality as a learning organization for members of the organization and as a learning space for the academic community, in order to live sustainably in the process of changing learning trends.

The quantitative method was applied in this study using benchmarking model of Garvin's learning organization. The results show that UGM Library has transformed to be a learning organization. Most of the indicators have reached, whereas some others are still below the standard of benchmark. Meanwhile there was difference in score based on level of education.

The study was the first time conducted at UGM Library within a certain period of time; therefore there is no description of comparison process between the past and now. In the future its is expected there is further measurement to identify the development of preparedness of UGMLibrary as a learning organization.
\end{abstract}

Keywords: Learning Organisation, University, Organizational Change, Learning Environment *) Pustakawan Universitas Gadjah Mada

**) Pemenang Hibah Penelitian Perpustakaan UGMtahun 2016

\section{A. PENDAHULUAN}

\section{Latar Belakang}

Perpustakaan merupakan salah satu unit penunjang universitas yang memberikan kontribusi pada pembelajaran, penelitian, dan pengabdian kepada masyarakat dengan penekanan pada layanan perpustakaan berbasis teknologi informasi dan komunikasi (Pemerintah RI, 2007; 2013; Perpustakaan UGM, 2016). Dengan demikian, Perpustakaan perguruan tinggi perlu menempatkan pembelajaran berbasis teknologi sebagai isu utama dalam setiap pengelolaan sumber dayanya, yakni sumber daya manusia, sumber daya infrastruktur, dan sumber daya informasi (Bennett, 2015).

Selama ini, Perpustakaan Universitas Gadjah Mada (UGM) sebagai bagian dari Universitas Gadjah Mada yang menduduki peringkat 1 di webometric Juli 2016 di Indonesia dan di urutan 724 tingkat dunia, berjalan beriringan dengan unit kerja lain untuk meningkatkan visibilitas institusi tingkat internasional. Kinerja dan inovasi secara berkelanjutan mampu menjaga institusi untuk keberlangsungan hidup organisasi di masa yang akan datang.

Salah satu faktor pendukung bagi kinerja dan inovasi sebuah organisasi adalah faktor pembelajaran secara terus menerus dalam organisasi itu sendiri (Senge, 1996; Garvin, 2008). Organisasi pembelajar bagi perguruan tinggi menurut Senge (1996) adalah organisasi yang memiliki kemampuan untuk mentransfer pengetahuan dan memodifikasi perilaku yang mencerminkan pengetahuan dan wawasan baru. Lebih lanjut, Garvin (2008) menambahkan perlunya menciptakan lingkungan yang kondusif bagi pembelajaran, proses dan praktik nyata pembelajaran, serta kepemimpinan yang memperkuat pembelajaran/mendukung pengembangan.

Beberapa penelitian menunjukkan bahwa sebuah organisasi yang belajar dari transfer informasi dan pengalaman anggotanya, berpengaruh pada beberapa faktor dalam organisasi, seperti komitmen pegawai terhadap organisasi (Dewi, 2004: 73), kemampuan dalam 
manajemen pengetahuan (Ho, 2008), dan kinerja organisasi (Ahmar, 2014; Som, 2010), serta keinovatifan organisasi. Oleh karena itu, penting untuk mengukur Perpustakaan sebagai organisasi pembelajar agar perpustakaan dapat memperbaiki kinerja dan inovasi dari dalam organisasi.

Berbagai perpustakaan telah memodifikasi beberapa faktor yang menjadi pilar dari organisasi pembelajar (Limwichitr, 2015), termasuk di dalamnya Nanyang Technology University (NTU) dan National and State Libraries Australasia (NSLA). Sementara itu, Perpustakaan NSLA memadatkan komponen menjadi 3 pilar yaitu learning and learners, vision and culture and management and structure. Komponen tersebut dipercaya mewakili karakteristik organisasi pembelajar yang disesuaikan dengan kondisi organisasi lokal.

Sampai dengan saat ini, Perpustakaan UGM belum melakukan dan mengembangkan pengukuran organisasi pembelajar bagi perpustakaan di lingkungan UGM. Oleh karena itu, penelitian ini difokuskan pada pengukuran Perpustakaan UGM sebagai organisasi pembelajar dengan menggunakan instrumen yang diadaptasikan dari survei organisasi pembelajar Garvin et.al (2008).

Instrumen pengukuran organisasi dari Garvin et.al (2008) dipilih dengan pertimbangan bahwa instrumen ini telah dipublikasikan dan diujicobakan di berbagai institusi, baik di luar negeri maupun di Indonesia. Sementara itu, sebagai organisasi, Perpustakaan UGM telah bermitra dengan institusi di lingkup nasional dan global, berikut juga pegawainya telah berkontribusi di lingkup nasional dan global (Perpustakaan, 2016).

\section{Rumusan Permasalahan}

Perubahan yang terjadi lingkungan Perguruan Tinggi, mendorong Perpustakaan untuk dapat menyesuaikan diri dengan cara menjadi organisasi pembelajar. Dengan demikian, penelitian ini mengukur faktor-fakor yang mendukung Perpustakaan UGM sebagai organisasi pembelajar dan perbedaan sebagai organisasi pembelajar berdasarkan tingkat pendidikan pegawai, serta status jabatan fungsional pegawai.

\section{Tujuan}

Adapun tujuan dari penelitian ini untuk mengidentifikasi dan menganalisis faktorfaktor yang mendukung Perpustakaan UGM dalam bertransformasi menjadi sebuah organisasi pembelajar, dengan dukungan tingkat pendidikan dan status jabatan fungsional pegawai, serta sebagai bahan penyusunan masukan bagi upaya Perpustakaan UGM dalam bertransformasi menjadi organisasi pembelajar.

\section{B. TINJAUAN PUSTAKA}

Istilah Organisasi Pembelajar (learning organization) diserap dari istilah perusahaan pembelajar (learning company) (Pedler et.al, 1988), yaitu

An organization which facilitates the learning of all its members and continuously transforms itself.

Jika dikaitkan dengan organisasi, maka sebuah organisasi pembelajar memiliki iklim yang mendorong individu anggotanya untuk belajar dan mengembangkan potensinya, memperluas budaya pembelajar ini kepada konsumen, pemasok, dan pihak-pihak terkait, menjadikan pusat strategi pengembangan sumber daya manusia menjadi kebijakan bisnis, dan selalu berada proses transformasi organisasi berkelanjutan.

Rowley (1997) menyatakan bahwa organisasi pembelajar adalah kunci utama dari seluruh kegiatan organisasi. Sedangkan, Garvin (2008) memberikan definisi organisasi pembelajar sebagai organisasi yang berkemampuan untuk mencipta, mengumpulkan, dan mentransfer pengetahuan, serta mengubahnya menjadi perilaku yang mencerminkan pengetahuan baru. Untuk itu, perlu menciptakan lingkungan yang kondusif bagi pembelajaran, proses dan praktik nyata pembelajaran, serta kepemimpinan yang memperkuat pembelajaran/mendukung pengembangan.

McCaffery (2010: 200) membedakan karakteristik organisasi pembelajar dan nonpembelajar ke dalam Tabel 1 seperti di bawah ini: 
Tabel 1. Karakteristik Organisasi Pembelajar dan Non-pembelajar

\begin{tabular}{|c|c|}
\hline Organisasi Pembelajar & Organisasi non-Pembelajar \\
\hline $\begin{array}{l}\text { Antisipasi Masalah di } \\
\text { Masa depan }\end{array}$ & $\begin{array}{l}\text { Bereaksi pada masalah saat } \\
\text { ini saja }\end{array}$ \\
\hline Menaruh perhatian pada & Menaruh perhatian hanya \\
\hline $\begin{array}{l}\text { lingkungan eksternal } \\
\text { organisasi }\end{array}$ & $\begin{array}{l}\text { pada lingkungan internal } \\
\text { organisasi }\end{array}$ \\
\hline $\begin{array}{l}\text { Pemecahan masalah } \\
\text { berdasarkan pemahaman } \\
\text { dan analisis konseptual }\end{array}$ & $\begin{array}{l}\text { Pemecahan masalah } \\
\text { berdasarkan coba-coba }\end{array}$ \\
\hline $\begin{array}{l}\text { Pemecahan masalah } \\
\text { berpusat pada masalah } \\
\text { dan organisasi luas }\end{array}$ & $\begin{array}{l}\text { Pemecahan masalah per- } \\
\text { bagian dan hirarkis }\end{array}$ \\
\hline $\begin{array}{l}\text { Apresiasi untuk } \\
\text { pertumbuhn, inisiatif dan } \\
\text { kreativitas }\end{array}$ & $\begin{array}{l}\text { Apresiasi pada kinerja } \\
\text { sebelumnya }\end{array}$ \\
\hline
\end{tabular}

Senge (1996) dalam teorinya The Fifth Dicipline menyatakan bahwa ada 5 (lima) hal penting dalam organisasi pembelajar yaitu Berpikir Sistem (System Thinking), Visi yang Terbagi (Shared Vision), Keahlian Personal (Personal Mastery), Model Mental (Mental Models), dan Pembelajaran Tim (Team Learning).

Demikian juga, pilar Pembangun Organisasi Pembelajar menurut Garvin et.al (2008) terdiri atas:

1. Pilar I: Lingkungan Belajar Supportif ( $A$ Supportive Learning Environment) yang terdiri atas Keamanan Psikologis (Psychological Safety), Penghargaan dan Apresiasi terhadap Perbedaan (Appreciation of Differences), Keterbukaan pada Ide-Ide Baru (Openness to New Ideas), Waktu Untuk Refleksi (Time for Reflection). Lingkungan belajar dalam hal ini lingkungan perpustakaan yang mendukung pembelajaran anggota organisasinya akan mendukung terciptanya Perpustakaan Pembelajar.

2. Pilar II: Proses dan Praktek Konkret Learning Organization (Concrete Learning Processes and Practices). Menaruh perhatian pada proses pembelajaran merupakan salah satu pembentuk organisasi pembelajar.

3. Pilar III: Kepemimpinan yang Memperkuat Pembelajaran (Leadership that Reinforces Learning). Perilaku pemimpin dan gaya kepemimpinan turut berpengaruh pada proses menjadi organisasi pembelajar (Dewi, 2013; Keriahen, 2014). Dalam organisasi pembelajar, pemimpin adalah perancang bangun, pembantu, dan guru sekaligus (Senge, 1996: 338). Menurut Garvin et. al. (2008). Pemimpin yang secara aktif bertanya, mendengarkan, dan berdialog dengan pegawai, dapat memotivasi pegawai untuk belajar terus menerus. Begitu juga pemimpin yang memandang penting untuk meluangkan waktu mencari solusi sebuah permasalahan, berbagi pengetahuan, dan bercermin pada hasil evaluasi, maka orang akan semakin terbiasa untuk menyampaikanide dan pilihannya.

\section{METODE PENELITIAN}

Metode yang digunakan dalam penelitian organisasi pembelajar ini yaitu metode penelitian kuantitatif dengan menggunakan skor pembanding (benchmark) Organisasi Pembelajar dari Garvin et al (2008).

Penelitian ini berlokasi di Perpustakaan Universitas Gadjah Mada yang telah menerapkan International Standard Organization (ISO) 9001:2008 dan ISO-Like untuk menjaga Standar Mutu Pelayanan dengan berbagai indikator kinerjanya (www.renbang.ugm.ac.id). Perpustakaan Universitas Gadjah Mada terdiri atas 18 (delapan belas) Perpustakaan Fakultas, 2 (dua) Perpustakaan Sekolah, dan 1 (satu) Perpustakaan Pusat.

Pemilihan sampel responden menggunakan cara purposive sampling, yaitu pemilihan informan dengan pertimbangan dan tujuan tertentu (Sugiyono, 2005: 216). Sampel penelitian diambil dari populasi pustakawan dan staf perpustakaan yang data kepegawaiannya berada di Perpustakaan Pusat Universitas Gadjah Mada berjumlah 116 orang (Perpustakaan, 2016). Data dikumpulkan dalam bentuk survei dan dokumen organisasi. Selanjutnya, data yang telah terkumpul dianalisis dengan menggunakan standar pembanding yang dikeluarkan oleh Garvin et.al. (2008).

Instrumen yang dipergunakan merupakan adaptasi dari penelitian organisasi pembelajar oleh Garvin et.al. (2008) yang dipublikasikan dalam Harvard Business Review, yang disebut Learning Organization Survey, dan dipublikasikan melalui laman web Harvard Business School. Komponen Learning 
Organization dan item pertanyaan Pilar I sebanyak 18, Pilar II sebanyak 28, dan Pilar III sebanyak 7. Setiap jawaban dari responden menggunakan skala Likert 1-7 pada Pilar I dan II dan 1-5 pada pilar III. Uji Validitas instrumen dilakukan dengan menggunakan rumus Pearson Product Moment. Instrumen dinyatakan valid jika nilai signifikansi 2 sisi $\leq 0.05$.

Penentuan skor individu Pilar I, II, dan III diperoleh mengkalikan jumlah pertanyaan dengan nilai 100 dan dibagi 7 untuk skala likert 1-7 dan 5 untuk skala likert 1-5. Selanjutnya jumlah skor individu dibagi dengan jumlah skor pertanyaan untuk mendapatkan skor komponen.

\section{HASIL DAN PEMBAHASAN}

\section{Demografi Responden}

Penelitian ini melibatkan pegawai yang kepegawaiannya berada di Perpustakaan Pusat. Responden sejumlah 114 pegawai, kuesioner diedarkan kepada sejumlah 109 pegawai dengan pertimbangan bahwa ada pegawai yang sedang menerima tugas belajar di luar institusi, sebagian pegawai yang terlibat dalam penelitian ini, dan tidak, sedangkan kuesioner yang dapat dipergunakan sebanyak 102 orang.

Selanjutnya, dari keseluruhan responden tersebut, memiliki tingkat pendidikan yang bervariasi, dari Sekolah Menengah Pertama (SMP) sederajat sebanyak 4,9\%, Sekolah Menengah Atas (SMA) sederajat sebanyak $20 \%$, Diploma II/III sebanyak 26,5\%, Sarjana S1 sebanyak 31,4\%, dan S2 sebanyak 17,6\%.

Berdasarkan masa kerja, terdapat 33,3\% responden dengan masa pengabdian $\leq 14$ tahun, $34 \%$ dengan masa pengadian 15-23 tahun, dan $32,4 \%$ dengan masa pengabdian $\geq 24$ tahun.

\section{Pilar I: Dukungan Lingkungan Pembelajar}

Secara umum, gabungan dari dukungan lingkungan pembelajaran menunjukkan angka 70 atau berada pada Kuartil Kedua mendekati median. Penghargaan atas perbedaan dan waktu untuk refleksi mendapatkan konfirmasi positif dari responden yaitu bernilai 69 yang berada pada Kuartil Ketiga. Artinya, kedua komponen tersebut perlu dipertahankan dan diusahan peningkatannya agar mencapai kuartil teratas. Sementara itu, penghargaan atas ide-ide baru tidak terkonfirmasi dengan baik oleh para responden. Meski penghargaan atas perbedaan mendapatkan nilai tinggi, namun hal tersebut bukan jaminan atas keterbukaan pada ide-ide baru yang disampaikan baik bagi staf perpustakaan dan pustakawan yang berada di lingkungan Universitas Gadjah Mada.

\section{Pilar II: Proses Dan Praktek Nyata Pembelajaran}

Pilar II ini mendapatkan skor gabungan rata rata sebesar 71 pada Kuartil Kedua. Hal ini menunjukkan bahwa proses dan praktek nyata pembelajaran tidak sepenuhnya dapat ditangkap informasinya secara baik oleh seluruh staf perpustakaan dan pustakawan. Praktek pengumpulan informasi berada di Kuartil bawah, artinya staf perpustakaan tidak melihat proses pengumpulan informasi secara sistematis terhadap pesaing, mencatat dan memprediksi tren teknologi informasi, serta sosial ekonomi untuk mendukung proses pengambilan keputusan.

\section{Pilar III: Kepemimpinan yang Mendukung Pembelajaran}

Kepemimpinan merupakan faktor yang penting dalam mengarahkan dan mewujudkan iklim sebuah organisasi. Hasil penelitian ini, menunjukkan bahwa Pilar III mendapatkan skor 74 atau berada pada Kuartil Kedua. Artinya, kepemimpinan di Perpustakaan UGM ini dipandang sudah mendorong pada iklim pembelajaran organisasi, meski masih harus berusaha lebih keras lagi untuk mencapai kriteria tertinggi sebuah organisasi pembelajar.

\section{Organisasi Pembelajar Berdasarkan Tingkat Pendidikan}

Pendidikan memberikan kontribusi pada pemaknaan sebuah organisasi pembelajar di Perpustakaan UGM seperti yang terpampang pada Bagan 4.1. Pada Pilar I, dukungan lingkungan pembelajaran menjadi catatan terbaik pada pegawai dengan tingkat pendidikan Diploma II/III dan S2 dengan nilai 72 , dua poin di atas rata-rata. Dengan demikian, lingkungan yang diciptakan saat ini memberikan rasa nyaman bagi pegawai sehingga mampu untuk memproduksi dan mengkomunikasikan ide-ide baru mereka. Hal tersebut berbeda dengan yang dirasakan oleh pegawai dengan pendidikan SMP dan SMA. Lingkungan belum memberikan kenyamanan 
yang cukup membuat orang mengalirkan ide segar bagi perbaikan kerja maupun kinerja organisasi secara keseluruhan.

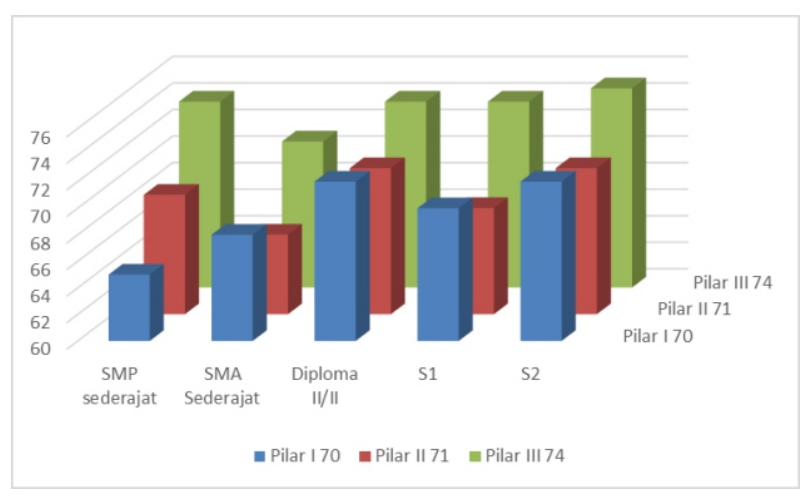

Bagan 4.1. Pilar I, II, dan III dalam Perbandingan Hasil Perolehan Pengukuran Berdasarkan Tingkat Pendidikan Pegawai

Pada Pilar II, hal yang juga terjadi pada pegawai dengan tingkat pendidikan Diploma II/III dan S2 dengan nilai 71, sama dengan skor rata-rata sebuah organisasi pembelajar. Praktek nyata percobaan, pendidikan dan pelatihan, serta transter informasi cukup dirasakan manfaatnya. Hal berbeda terjadi dengan pegawai dengan tingkat pendidikan SMA yang belum merasakan kondisi dan manfaat dari pilar II ini.

Pilar III menunjukkan bahwa hampir semua pegawai di seluruh jenjang pendidikan menyatakan kepemimpinan yang dirasakan selama ini mendukung pada pengembangan diri dan organisasi melalui proses pembelajaran. Skor yang dihasilkan hanya selisih $1-4$ poin saja.

\section{Organisasi Pembelajar Berdasarkan Karakteristik Status Jabatan}

Karakteristik Status Jabatan Responden antara pustakawan dan non-pustakawan berkontribusi pada perbedaan skor gabungan rata-rata dengan skor gabungan rata-rata Benchmark. Pustakawan merasakan lingkungan Perpustakaan UGM yang mendukung pembelajaran. Hal ini ditunjukkan pada Bagan 4.2 dengan skor yang diberikan lebih tinggi 2 poin dari skor gabungan rata-rata hasil penelitian secara umum. Berkebalikan dengan pegawai non-pustakawan yang skornya berada 2 poin di bawah skor gabungan rata-rata Perpustakaan UGM.

Pada Pilar II, skor pustakawan sama

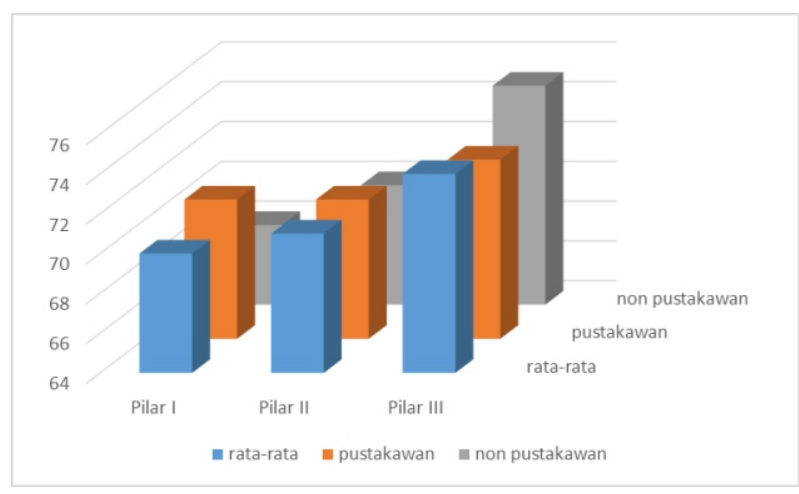

Bagan 4.2. Pilar I, II, dan III dalam Perbandingan Hasil Perolehan Pengukuran Berdasarkan Status Jabatan Fungsional

dengan skor gabungan rata-rata hasil penelitian secara keseluruhan, sedangkan non-pustakawan berada di bawah satu poin skor gabungan ratarata. Sementara itu, hal yang berkebalikan terjadi pada Pilar III, dimana skor pustakawan 1 poin berada di bawah skor gabungan rata-rata hasil penelitian dan skor non-pustakawan lebih tinggi 1 poin dari skor gabungan.

\section{Pembahasan}

Lingkungan yang mendukung pembelajaran pada Perpustakaan UGM terutama pada komponen penghargaan pada perbedaan dan waktu untuk refleksi, sesuai dengan penelitian Keriahen (2014) dan Lendo (2014). Artinya, pegawai merasa nyaman untuk menyampaikan pendapat atas permasalahan kerja baik di forum formal maupun informal, menghargai cara kerja yang berbeda dalam menyelesaikan pekerjaan, dan memiliki waktu untuk mencerna berbagai informasi dan kerja, serta tidak terjebak pada rutinitas.

Komponen lingkungan yang perlu diperhatikan lebih lanjut adalah keterbukaan pada ide-ide, sesuai dengan penelitian sesuai dengan penelitian Keriahen (2014) dan Lendo (2014). dan keamanan psikologis anggota organisasi, sesuai dengan penelitian Lendo (2014). Semakin nyaman seseorang secara psikologis, maka makin produktif dan berani dalam menerima dan mempertukarkan ide-ide baru di dalam organisasi, serta tidak resisten terhadap perubahan. Hasil ini sama dengan penelitian Lendo (2014) menurutnya, hal tersebut disebabkan adanya penerapan reward dan punishment, orang tertarik untuk mendapatkan reward, namun merasa perlu 
berhati-hati untuk tidak mendapatkan hukuman karena melakukan kesalahan dalam kerja.

Pada proses dan praktik nyata pembelajaran, Perpustakaan UGM unggul di komponen transfer informasi dan analisis melampaui skor median dalam skor benchmark Garvin et. al. (2008). Berikut komponen percobaan yang sama dengan skor median dalam skor benchmark Garvin et. al. (2008). Beberapa tahun terakhir, ada proses ujicoba pada inovasi yang diinisiasi di Perpustakaan UGM. SIPUS Integrasikan diujicobakan di 4 (empat) perpustakaan saja di awal implementasinya (Wahyuni, 2016), berikut kebijakan unggah mandiri, pemberlakuan single ID Card untuk anggota perpustakaan, dan sebagainya. Yang paling bawah adalah pengumpulan informasi terkait lingkungan eksternal guna mendukung pengambilan keputusan organisaasi.

Proses pembelajaran di Perpustakaan UGM dikomunikasikan dengan menggunakan berbagai media (Wahyuni, 2016), mulai dari pertemuan tatap muka, telepon, surat cetak, sampai dengan menggunakan media baru seperti media sosial dan surel. Media sosial digunakan untuk berbagi informasi terkini tentang proses integrasi SIPUS tersebut di antara penanggung jawab perpustakaan dan tim pengelola proyek tersebut. Akan tetapi, tidak semua informasi terkini tersebut terbagi kepada seluruh anggota organisasi Perpustakaan UGM. Masih ada sebagian anggota yang tidak mengetahui secara persis perkembangan terkini terkait inovasi tersebut, terutama pegawai yang tidak terlibat secara langsung dalam proses integrasi (Perpustakaan UGM, 2016). Dengan demikian, tidak semua proses transfer informasi berjalan dengan baik, sehingga tidak semua perubahan yang terjadi Perpustakaan terinformasikan kepada seluruh pegawai di Perpustakaan UGM.

Proses dan praktik nyata pembelajaran telah dilakukan di Perpustakaan UGM. Transfer informasi, pendidikan, dan pelatihan terjadi dalam berbagai bentuk kegiatan. Di tahun 2015, terdapat 56 (lima puluh enam) kegiatan workshop/seminar, dan lain-lain yang diikuti staf perpustakaan (sebagai peserta) dan diselenggarakan oleh pihak di luar Perpustakaan UGM (Perpustakaan UGM, 2016: 51-56). Sementara itu, Perpustakaan UGM sendiri telah menyelenggarakan 29 workshop/seminar/pelatihan yang diadakan di lingkungan UGM bagi mahasiswa, dosen, dan pegawai (Perpustakaan UGM, 2016: 60-64).

Pendidikan dan pelatihan dilakukan secara rutin di Perpustakaan UGM, terutama bagi pustakawan. Kehadiran Forum Pustakawan UGM sebagai wadah berbagi informasi dan pelatihan bagi pustakawan dilaksanakan hampir setiap bulan dengan didukung oleh komitmen pendanaan dari Perpustakaan UGM. Di tahun 2015, telah dilakukan transfer informasi untuk seluruh pegawai (pustakawan dan nonpustakawan) sebanyak 9 (sembilan) workshop /seminar/bedah buku, 3 (tiga) diantaranya khusus untuk pustakawan (Perpustakaan UGM, 2016: 60-64). Perpustakaan UGM sendiri menyelenggaran 1(satu) workshop /FGD bagi seluruh pegawai dan 3 (tiga) workshop/FGD/TOT bagi pustakawan. Ketidakserimbangan ini tercermin dalam perbedaan skor antara pustakawan dan nonpustakawan pada Pilar II.

Pilar III, kepemimpinan yang mendukungan pembelajaran berada pada Kuartil Kedua atau berada di bawah median. Semakin pegawai merasa nyaman dengan lingkungan perpustakaan dan merasakan pengalaman nyata dalam proses pembelajaran, maka semakin tinggi harapannya pada kepemimpinan yang ada. Pemimpin dalam organisasi pembelajar adalah pembuat rancang bangun, pembantu, dan guru (Senge, 1996: 338). Seringkali pemimpin sebagai pendesain tidaklah nampak, karena yang terlihat saat ini adalah hasil pekerjaan yang telah dilakukan jauh di masa lampau, sedangkan pekerjaan saat ini akan nampak di masa yang akan datang (1996: 339). Dengan demikian, hasil penelitian ini bukanlah semata-mata merupakan potret kepemimpinan saat ini saja, namun potret kepemimpinan selama ini yang dialami oleh para pegawainya.

\section{E. KESIMPULAN DAN SARAN Kesimpulan}

Berdasarkan pembahasan di atas, Perpustakaan UGM memiliki beberapa praktek baik dalam upayanya menjadi sebuah organisasi pembelajar. Beberapa peluang peningkatannya adalah sebagai berikut:

a. Pilar I, Dukungan Lingkungan Pembelajaran, menunjukkan bahwa Perpustakaan UGM telah mencapai Kuartil 
Ketiga yang berada di atas Skor rata-rata Benchmark pada komponen ketersediaan waktu untuk refleksi dan penghargaan atas perbedaan dalam proses pembelajaran individu dan organisasi. Kuartil Kedua yang berada di bawah Skor rata-rata Benchmark pada komponen keamanan psikologis dan penghargaan atas perbedaan. Sementara itu, Kuartil Bawah yang berada di bawah Skor rata-rata Benchmark pada komponen keterbukaan pada ide-ide baru.

b. Perpustakaan UGM pada Pilar II, proses dan praktik nyata pembelajaran, mencapai Kuartil Kedua yang berada di atas Skor Rata-rata Benchmark. Perpustakaan UGM telah mencapai Kuartil Ketiga yang berada di atas Skor rata-rata Benchmark pada komponen Transfer Informasi. Perpustakaan UGM telah mencapai Median atau sama dengan Skor rata-rata Benchmark pada komponen melakukan percobaan pada saat inovasi dikomunikasikan pada anggota organisasi. Kuartil Kedua yang berada di bawah Skor Rata-rata Benchmark pada komponen proses analisis permasalahan secara komprehensif, pendidikan dan pelatihan yang selama ini telah berjalan rutin bagi pegawai.

c. Perpustakaan UGM pada Pilar III, Kepemimpinan yang Memperkuat Pelatihan, mencapai Kuartil Kedua yang berada di bawah Skor Rata-rata Benchmark

d. Perbandingan hasil perhitungan skor gabungan rata-rata Pilar I, Pilar II, dan Pilar III dan Skor organisasi pembelajar berdasarkan karakteristik pendidikan pegawai menunjukkan bahwa ada perbedaan penilaian dari pegawai yang berpendidikan SMP/SMA sederajat, DII/DIII, S1, dan S2.

e. Perbandingan hasil perhitungan skor gabungan rata-rata Pilar I, Pilar II, dan Pilar III dan Skor organisasi pembelajar berdasarkan karakteristik jabatan fungsional pegawai menunjukkan bahwa ada perbedaan penilaian dari pegawai yang berstatus pustakawan dan non-pustakawan.

\section{DAFTAR PUSTAKA}

Ahmar, G. O. A., Rofiq A., \& Hadiwidjojo, D. (2014). The impact of knowledge management, learning organization, and educations organization on organization performance: A case in Brawijaya University. Asia-Pacific Management and Business Application 3(1) 28 - 47. Retrieved from http://apmba.ub.ac.id.

Bennett. S. (2015). Putting Learning into Library Planning, Libraries and the Academy, 15(2), pp. 215-231.

Dewi, P.S. (2013). Hubungan antara Leader Member Exchange dan Budaya Learning Organization dengan Komitmen Organisasi, Tesis, Universitas Gadjah Mada.

Garvin, D. A., Edmondson, A. C., \& Gino, F. (2008). Is yours a learning organization?: a Tool Kit. Diakses dari http://provost. tufts.edu/celt/files/Is-Yours-a-LearningOrganization-by-Garvin-Edmondson-andGino.pdf.

Ho, L. (2008). What affects organizational performance, Industrial management DataSystems, 108(9), pp. 1234-1254.

Keriahen, Y. (2014). Analisis pengukuran learning organization dan langkah strategis peningkatannya program studi strata satu fakultas ekonomi dan bisnis universitas Bengkulu (Tesis S2 tidak dipublikasikan). Universitas Gadjah Mada, Yogyakarta, Indonesia.

Lendo, F. B. (2014). Analisis implementasi learning organization Ditinjau dari three building blocks of the Learning organization: Studi pada PT. Gama Multi Usaha Mandiri (Tesis S2 tidak dipublikasikan). Universitas Gadjah Mada, Yogyakarta, Indonesia.

Limwichitr, S., Broady, J., \& Ellis, D. (2005). A Discussion Of Problems in Implementing Organisational Cultural Change Developing a Learning Organisation in University, Libraries, Library Review, 64(6/7), pp. 480-48, Emerald Group Publishing Limited DOI 10.1108/LR-102014-0116.

McCaffery, P. (2010). The higher education manager's handbook: Effective leadership and management in universities and colleges. New York: Routledge. 
Rowley, J. (1997). The library as a learning organization, Library Management, 18 (2), pp. 88-91. MCB University Press

Senge, P. M. (1996). Disiplin Kelima: Seni dan Praktek dari Organisasi Pembelajar. Jakarta: Binarupa Aksara.

Som, H., Saludin, M. N., Shuib, S., Keling, M. F., Ajis, M. N., \& Nam, R. Y. T. (2010). Learning organization elements as determinants of organizational performance of non-profit organizations (NPOs) in Singapore. International NGO Journal, 5(5), pp. 117-128. Retrieved from http:// www.academicjournals.org/INGOJ

Sugiyono. (2010). Statistika untuk Penelitian. Bandung: Alfabeta.

Pedler, M., Boydell, T. and Burgoyne, J. (1988), Learning Company Project Report, Training Agency, Sheffield.

Pemerintah RI. (2013). Peraturan Pemerintah Nomor 67 Tahun 2013 tentang Statuta $U G M$.

Perpustakaan UGM. (2016). Daftar Peserta Workshop Peningkatan Mutu Layanan Perpustakaan Universitas Gadjah Mada, 14-15 Mei 2016.
Perpustakaan UGM. (2016). Laporan Perpustakaan Universitas Gadjah Mada Tahun 2015: Optimalisasi Peran SDM Perpustakaan dalam Mendukung Pencapaian Misi dan Visi Universitas Gadjah Mada, disampaikan pada Acara Peringatan Dies Natalis ke-65 Perpustakaan Universitas Gadjah Mada 2016.

Universitas Gadjah Mada. (2011). Tiga puluh layanan Kantor Pusat UGM bersertifikat $I S O$. Diakses dari http://renbang. ugm.ac.id/site/node/25.

Universitas Gadjah Mada. (2015). Surat Edaran Nomor 2084/PIV/PSDM/2016 tentang Bantuan Studi Lanjut bagi Tenaga Kependidikan, tanggal 01 Juni 2015.

Universitas Gadjah Mada. (2016). Surat Edaran Nomor 1888/UN1.P.IV/SDM/DA/2016 tentang Bantuan Studi Lanjut bagi Tenaga Kependidikan, tanggal 15 Maret 2016.

Wahyuni, N. C. (2016). Adopsi Inovasi Sistem Informasi Perpustakaan Universitas Gadjah Mada: dari perspektif Teori Difusi Inovasi dan Resource-Based View (Tesis S2 tidak dipublikasikan). Universitas Gadjah Mada, Yogyakarta, Indonesia. 